\title{
De la afinidad electiva entre la teoría sociológica de Luhmann y la antropología filosófica alemana
}

\author{
ELECTIVE AFFINITY BETWEEN THE SOCIOLOGICAL THEORY OF LUHMANN AND THE GERMAN PHILOSOPHICAL \\ ANTHROPOLOGY
}

Dr. Patricio Miranda (patriciomiranda@uc.cl) Escuela de Trabajo Social, Pontificia Universidad Católica de Chile (Santiago, Chile)

\begin{abstract}
The article argues for the existence of an elective affinity between the systems theory of Niklas Luhmann and German philosophical anthropology, affinity that would bring to light (a-letheia) a 'blind spot' of the functionalism of the equivalence that is placed in the antithesis of the so called anti humanism in Luhmann. The question asked by the German sociologist: which self-projection of man is behind the assumptions of functionalist thinking? He responded: the man as problem solver in a transcendental sense. As well as in Goethe elective affinity of a 'new' theoretical content with pre-existing materials, in the case that concerns us, such pre-existing materials would have had a known address, so that the originality of Luhmann would be in a new composition of categories. The new luhmannian composition takes shape, at least in the following arguments: the distinction from man/environment to the distinction system/environment; the turn from contingency to double contingency; complexity and its reduction in German philosophy to complexity and its reduction in systems theory; from categories of self-reference and self-observation to the theory of the observer; the offset of the human and the world to the offset of society; the functionalism of the German philosophy to the functionalism of the equivalence.
\end{abstract}

Key words: German philosophical anthropology, elective affinity, systems theory, Luhmann, functionalism.

\section{Resumen}

El artículo postula la existencia de una afinidad electiva entre la Teoría de Sistemas de Niklas Luhmann y la Antropología Filosófica Alemana (AFA), afinidad que traería a la luz (a-letheia) un 'punto ciego' del funcionalismo de la equivalencia que se coloca en la antítesis del mentado antihumanismo luhmanniano. A la pregunta que el mismo sociólogo alemán se planteaba: ¿qué autoproyección del hombre está detrás de las suposiciones del pensamiento funcionalista?, se respondía: el hombre como solucionador de problemas en un sentido trascendental. Tesis antropológica central de la AFA. Así como en Goethe afinidad electiva dice de una 'nueva composición' teórica con materiales prexistentes, en el caso que nos ocupa, 
tales materiales preexistentes tendrían domicilio conocido, de modo que la originalidad de Luhmann estaría en una nueva composición de categorías de una tradición antropológica muy desarrollada en su época y país. La nueva composición luhmanniana toma forma, al menos, en los siguientes desplazamientos argumentales: de la distinción hombre/entorno a la distinción sistema/entorno; del giro a la contingencia al giro a la doble contingencia; de la complejidad y su reducción en la AFA a la complejidad y su reducción en la teoría de sistemas; de las categorías de autorreferencia y de autoobservación a la teoría del observador; del descentramiento de lo humano y del mundo al descentramiento de la sociedad; del funcionalismo de la AFA al funcionalismo de la equivalencia.

Palabras clave: antropología filosófica alemana, afinidad electiva, teoría de sistemas, Luhmann, funcionalismo

\section{Introducción}

Hablar de afinidad electiva no constituye una novedad en la investigación sociológica. Introducida por Goethe en Las afinidades electivas, su fructífera recepción en el campo de la sociología se inscribe en el diálogo con la literatura; diálogo propiciado por "la coincidencia que se da a veces (...) entre la obra sociológica y la literaria a la hora de abordar -cada una con sus medios o su método- un determinado tema u objeto de estudio" (Fuster 2009:62). Goethe dirá que una afinidad electiva dice tanto de una separación como de "una nueva composición" (Goethe 2000:28), con lo que puede comprender como una relación simbólica que desborda el campo semántico de los elementos que se ponen en relación en un lenguaje diferente. $Y$ tal tipo de relación no causalista es la que Weber plausibiliza entre la ética protestante y el 'espíritu' del capitalismo al responder la interrogante de "si se puede encontrar y en qué puntos, una determinada afinidad electiva entre ciertas formas de fe religiosa y la ética profesional" (Weber 2003:107). En términos luhmannianos la búsqueda de afinidades electivas encuentra su sustento en el método de equivalentes funcionales, en tanto que pretender "una absoluta incomparabilidad [entre teorías] revela siempre falta de fantasía teórica” (Luhmann 1997:101).

¿Por dónde iniciar un ejercicio de fantasía teórica con la obra del sociólogo alemán? Por cierto, no al interior de la tradición conceptual de la sociología, sino fuera; camino obligado para un teórico que se propone "revolucionar el paradigma de la teoría de la sociedad" (Luhmann 2007:40). Los desarrollos de la teoría de sistemas, de la cibernética, de la biología, de las ciencias cognitivas, de la teoría de la comunicación, de la teoría la evolución, de la lógica matemática y de la filosofía, serían los campos de exploración extra muros. La lectura de una obra temprana de Luhmann, llustración sociológica y otros ensayos, despertó nuestra fantasía teórica y nos indujo a pensar que en ella, en el esfuerzo intelectual de liberar el concepto de función de todo lastre de causalidad, nuestro autor ofrecía una clave hermenéutica fructífera, condensada en el epítome 'pensamiento funcionalista'. El interrogante que él mismo formula: “¿qué autoproyección del hombre está detrás de las suposiciones del pensamiento funcionalista?" (Luhmann 1973:57), sumado a su tesis de que "mucho antes de que el hombre concibiera investigar empíricamente su pensamiento como proceso de la solución de problemas, se consideró solucionador de problemas en un sentido trascendental y puso como base las suposiciones fundamentales de la teoría sociológica" (Luhmann 1973:57), nos llevaron a indagar por el origen de esa peculiar comprensión de lo 
humano. Es así que la metáfora de lo humano, subyacente en el funcionalismo de la equivalencia luhmanniano, esto es, el ser humano como solucionador de problemas en un sentido trascendental, nos llevó a encontrarnos con un filón inexplorado: la Antropología Filosófica Alemana (AFA).

\section{La antropología filosófica alemana}

La Antropología Filosófica Alemana (AFA) tiene una larga historia, que se remonta a Herder y Hegel, conectando en el siglo XIX Feuerbach, Marx y Nietzsche. Sus inmediatos antecedentes están en la aplicación del método fenomenológico a la antropología filosófica en los últimos trabajos de Max Scheler. La expresión "antropología filosófica" comienza a ser usada por autores como Max Scheler y Helmuth Plessner, para significar una nueva 'philosophia prima' que genere una nueva síntesis entre los desarrollos científicos y humanistas sobre el hombre. Más allá de si (con Habermas) se puede hablar o no de diversas antropologías filosóficas, es reconocible un "Core Identity of Philosophical Anthropology" (Fischer 2009:153). Core Identity que se distingue por: su referencia teórica interna a la investigación prevalentemente biológica, desde donde se abre a otros desarrollos disciplinarios incluida la sociología; su convergencia en considerar la vida como "'círculo de funciones' entre un organismo y su entorno" (Fischer 2009:164); su comprensión del ser humano como "una criatura acabada solo a medias por la naturaleza" (Landmann citado en Raulet 2009:100), en virtud de lo cual el hombre no crea 'la' cultura, sino que crea una cultura y las culturas, precisamente porque es 'no fijado', 'culturalmente polimorfo', contingente en sus modus vivendi (Landmann) y su "enfoque evolucionista" (Sobrevilla 2006:112).

\section{Afinidad electiva entre la teoría sociológica luhmanniana y la AFA}

Este acápite trabaja tanto las anticipaciones categoriales (continuidades) como las discontinuidades que dicen de una 'nueva composición' (Goethe 2000:28) teórica de carácter sociológica operada por Luhmann y rastreable en una gran diversidad de sus obras. Exponemos aquí abreviadamente algunos desplazamientos conceptuales de la 'nueva composición' que Luhmann realiza a partir de la constelación conceptual de la AFA (1): de la distinción hombre/entorno a la distinción sistema/entorno; del giro a la contingencia al giro a la doble contingencia; de la complejidad y su reducción en la AFA a la complejidad y su reducción en la teoría de sistemas; de las categorías de autorreferencia y de autoobservación a la teoría del observador; del descentramiento de lo humano y del mundo al descentramiento de la sociedad; del funcionalismo de la AFA al funcionalismo de la equivalencia. Excluimos aquí por razón de espacio los desplazamientos del paradigma de la acción, al paradigma de la comunicación, de la atribución de sentido como 'proceso de delimitación' al sentido como 'selección de posibilidades' y de la descripción de transformaciones de lo moral en la sociedad moderna a una sociología funcionalista de lo moral.

\section{De la distinción hombre/entorno a la distinción sistema/entorno}

Plessner, desde su categoría central de 'posicionalidad' y 'posicionalidad excéntrica' en el caso del hombre, define la vida en términos de 'bordes' o 'límites'. La diferenciación de su respectivo entorno es condición de posibilidad para los diversos grados de la vida orgánica. La distinción hombre/entorno corresponde a la característica de un ser vivo que existe en el 'borde' entre su cuerpo y su correspondiente entorno, es 
decir, en su 'posicionalidad excéntrica'. Este descubrimiento coloca al hombre ante el imperativo de establecer límites artificiales con su entorno. Tales límites artificiales se extienden a la sociedad, la historia, la política, el lenguaje, el arte, la música, etc. El 'límite', el 'borde', la 'distancia', la 'discontinuidad', es señal de un ser que no tiene ninguna relación inmediata, ni siquiera consigo mismo, de allí que, la clave de bóveda de toda hermenéutica resida en que "solo a partir de lo extraño, podrá el hombre ver algo en sí mismo" (Villacañas 2004:71). Consiguientemente, los diversos grados de la vida y de lo orgánico, tienen como precondición para su propia constitución una operación de diferenciación: el diferenciarse de su entorno. Y nótese que la distinción hombre/entorno opera hacia afuera y hacia adentro. El entorno externo es el mundo; el entorno interno es el propio cuerpo.

En Gehlen la distinción sistema-entorno se ve reflejada en la incidencia operativa de conciencia (sistema psíquico) y procesos orgánicos (sistema orgánico). "Si la conciencia -nos dirá- está esencialmente vuelta al mundo, también, al revés, todos los procesos y realizaciones de la vida son inconscientes; transcurren en la oscuridad del inconsciente y se nos oculta el 'cómo' se desarrollan" (Gehlen 1980:80). La conciencia no es capaz de conocer los procesos orgánicos que presupone, ni es tal su destino. El mérito de este trascendental descubrimiento lo atribuye Gehlen a Schopenhauer, cuyo gran hallazgo fue "el describir el cuerpo como 'sujeto-objeto'; como un algo dado (simultáneamente por dentro y por fuera), que puede concebirse en unas ocasiones como activo en relación con el mundo exterior y otras veces como parte de ese mundo exterior; reaccionando a sí mismo y a las cosas externas" (Gehlen 1980:194). Se podría afirmar que bastaría con una transposición del descubrimiento plessneriano -prolongado en Gehlen- desde los diversos grados de lo orgánico y el hombre hacia los sistemas sociales y obtendríamos una fundamental afinidad electiva con la sociología luhmanniana. Plessner no podía dar este salto en su teoría de la sociedad, al concebir ésta como un sistema social de interacciones y de realización de objetivos sociales por parte de los individuos (tesis característica del individualismo metodológico, extraño a Luhmann).

\section{Del giro a la contingencia al giro a la doble contingencia}

Scheler fue el primero en la tradición de la AFA en derivar de su indagación sobre el puesto del hombre en el cosmos, la categoría de contingencia. Su comprensión de ser humano como ser abierto al mundo le conduce a descubrir "la contingencia del mundo y [el] extraño caso de su propio ser, excéntrico al mundo" (Scheler 1938:111).

Plessner deriva la categoría de contingencia de una de sus aportaciones teóricas más originales: la 'posicionalidad excéntrica'. Es la excentricidad de su posicionalidad la que arroja al ser humano al mundo de la contingencia del mundo y de sí mismo. La vida de un ser así “implica selección: la exclusión de algunas posibilidades en favor de otras" (Greene 1966:54). Implica no pertenecer al reino de lo irrevocable, puesto que la misma indeterminación originaria -escribe Plessner- "no consiente una valoración definitiva, sino que se protege de cualquier determinación y formulación de su esencia individual [pues] detrás de cada determinación de nuestro ser descansan las posibilidades inefables de ser-otro" (Menegazzi 2010:293). La condición des-centrada del ser humano lo conduce a un equilibrio inestable de lugar y tiempo; más aún, le cierra la posibilidad de contar con un tiempo y un lugar propio en el cual cobijarse fuera de la intemperie de la contingencia. 
Gehlen deriva la contingencia del 'principio de descarga', la imposibilidad de un modo unívoco de 'descargarse' para un ser simultáneamente deficitario y pulsionalmente excedido. Las 'descargas' del 'animal carencial' son, y no pueden ser de otra manera, no necesarias. En esta verdadera dialéctica de la condición humana está la ontogénesis de la condición contingencial del ser humano y sus mundos posibles.

En la segunda generación de esta tradición antropológica, Marquard pasa directamente de su confesado y defendido escepticismo de la vita brevis, a la contingencia. Aquí contingencia dice de la defensa de la pluralidad de formas de vida, de juegos de lenguajes, de mundos de la vida, de modus vivendi, en tanto garantes de la libertad del individuo frente a la realidad y a sus propias convicciones; del reconocimiento de la inevitabilidad de los hábitos (formas estabilizadas de conjurar la contingencia evitando nombrarla) $y$, finalmente dice de la aceptación de nuestra propia contingencia. Distingue dos tipos de contingencia: la 'contingencia destinal', que corresponde a "lo que en principio podría haber sido de otra manera en mi vida, pero de hecho no puedo cambiar" (Marquard 2000:139), haber nacido, por ejemplo, y la 'contingencia arbitraria', que corresponde a todo aquello que sí podemos hacer (o no) de otra manera. Estas dos especies de contingencia nos protegen del riesgo de absolutización de nosotros mismos y/o de alguna de nuestras creaciones ficcionales, necesarias sin embargo, para el viviente humano.

La vita brevis nos recuerda, cuando estamos dispuestos a mirarla a los ojos, que "no tenemos tiempo para confirmar o abandonar de una manera absoluta lo que ya somos de una manera contingente. Por tanto, tenemos que hacernos a la idea de que siempre vamos a ser más nuestros hábitos que nuestra elección" (Marquard 2000:16). El ser humano de Marquard es simultáneamente un cúmulo de 'contingencias destinales' y de 'contingencias arbitrarias' en las que tienen cabida las propias realizaciones. Para soportar la contingencia se requiere de formas compensatorias como la risa y el llanto, y no en último lugar, la renuncia al esfuerzo por parecer tonto. La apología de lo contingente, como reza una de las obras de Marquard, protege al ser humano de las múltiples figuras del absoluto. Una de esas, cara a la modernidad ilustrada, es de carácter epistemológico y dice de la pretensión de un saber absoluto, que no acepta su provisoriedad plural. No resulta así extraño que dirija una ácida crítica, entre otros, a Apel y Habermas, por su neokantiana pretensión de un fundamento trascendental del saber y de las normas procedimentales con pretensión de universalidad.

A su tiempo, Blumenberg partiendo del diagnóstico de vivir en la era del reconocimiento del giro moderno de la razón a la contingencia y de la llamada 'conciencia metafórica del hombre', sostendrá que el mundo y el sí mismo "no es el reflejo de ningún ser, sino la obra de su actividad fabricadora y creadora" (Flórez 2003:268). La carencia de fundamento del hombre blumenbergiano le lleva a la tarea de "crearse un medio en el que poder superar su miedo a la existencia fáctica y contingente; y ese medio es el 'mundo de la vida', en el que el hombre encuentra el refugio para su existencia" (Flórez 2003:268). "El mundo de la vida es, para Blumenberg, la encarnación de la no-contingencia" (González Cantón 2004:233). Al igual que Luhmann, Blumenberg considera que el origen de esta moderna categoría de contingencia reside en la deconstrucción nominalista del Dios cristiano fundada en la noción de creatio, que desde el mito-logos judeocristiano afirma "la condición óntica de un mundo hecho de la nada y señalado para su fin, mantenido en la existencia solo por voluntad divina" (González Cantón 2004:97). De modo que, paradójicamente, "la 
'cultura de la contingencia', que sella la cultura moderna y acaso postmoderna, se caracteriza por la idea fundamental de que lo que existe no tiene por qué existir necesariamente" (Blumenberg citado en González Cantón 2004:97).

Pero ninguno de los representantes de la AFA llega a tematizar la doble contingencia; allí vemos otro indicio de la nueva composición sociológica de Luhmann.

\section{De la complejidad y su reducción en la AFA a la complejidad y su reducción en la teoría de sistemas}

Gehlen, desde los inicios de su obra, comprende simultáneamente al hombre como un solucionador de problemas y como un sistema de funciones. En El hombre, su naturaleza y su lugar en el mundo, caracterizaba, siguiendo a Herder, al ser humano como un 'ser carencial' a nivel instintual y 'pulsionalmente excedido', de modo que la única manera de sobrevivir es descargándose con su propia agencia, actuando y seleccionando posibilidades siempre contingentes. Es su "vacío y carencias" (Gehlen 1980:96), el aguijón que lleva a Gehlen a la que denomina como 'ley estructural' presente en la construcción de todas las operaciones humanas: el 'principio de descarga' según el cual "todas las carencias de la constitución humana son transformadas por el hombre, por sí mismo y con su acción, en medios de su existencia" (Gehlen 1980:41). El hombre se presenta así como un ser reducidor y creador de posibilidades con lo que tiene a la mano, lo que le abre la posibilidad de mundos no unívocos. Las 'fijaciones' son formas contingentes de asegurar una sobrevivencia siempre amenazada por su condición carencial originaria. La cultura aparece de este modo como un artificio, una "mundanidad artificial" (Pansera 2005:73), que deriva del esfuerzo de transformar la naturaleza en algo "útil para la vida" (Gehlen 1980:42). Todas las operaciones humanas quedan sometidas a esta ley estructural de la condición humana.

Marquard proyectará el principio de descarga a los sistemas en la sociedad: ahora no es el ser humano el que compensa sus carencias descargándose, ya sea en la cultura y/o en las instituciones, sino que son los sistemas los que compensan sus carencias reduciendo complejidad. Más explícitamente, para Marquard, lo que Plessner, Gehlen y Sartre sostuvieron sobre el imperativo de la 'descarga' sigue operando en una sutil generalización en Niklas Luhmann. "También y precisamente el sistema 'ser humano' -agregarácompensa la sobrecarga de complejidad mediante la reducción de la complejidad" (Marquard 2000:44).

Schelsky, por su parte, reaccionado contra "el institucionalismo autoritario de su maestro [Gehlen] rehabilita al sujeto autónomo" (Raulet 2009:99). Con tal propósito emprende la búsqueda de una nueva teoría sociológica que articule integración y conflicto, subjetividad e instituciones. Pero su alumno Luhmann "saldrá por la tangente al pasar por alto el sujeto e intervenir la problemática: ya no es el hombre el que es descargado de sus deficiencias por las instituciones, son las instituciones las que, como sistemas autopoiéticos, se desembarazan de la molesta subjetividad" (Raulet 2009:99). Aquí reside una novedosa composición teórica: se ha producido el desplazamiento de la descarga de los seres humanos a la descarga de los sistemas y, muy especialmente, a la descarga de la molesta subjetividad en los sistemas sociales. 


\section{De las categorías de autorreferencia y de autoobservación a la teoría del observador}

En la perspectiva gehleliana, "el mundo perceptivo que vemos alrededor de nosotros cuando abrimos los ojos es totalmente el resultado de la actividad humana [fruto de nuestra propia industria en tanto] todas las operaciones humanas sensomotoras son auto-captadas, es decir, reaccionan a sí mismas y entre sí y son capaces de intercambio" (Gehlen 1980:44). El llamado 'mundo interior', pletórico de 'fantasmas de intercambio y de movimiento', de 'representaciones', de 'resultados favorables', de 'expectativas', de 'impresiones', etc., puede ser desarrollado y edificado independientemente del estado objetivo de la situación real. La independencia de tal estado de 'realidad' se deriva de la autoindustria agencial del ser humano, en virtud de la cual éste crea "en torno a sí el 'espacio vacío' de un mundo abarcable con la mirada (super-visible; por tanto, se puede prescindir también de él), rico e insinuaciones y colocado-ahí a disposición" (Gehlen 1980:44). El mundo dado-a-la-mano es edificado como consecuencia de los propios movimientos de experimentación, "en los que sin presión pulsional y sin satisfacer los impulsos 'jugando'- las cosas entran en la experiencia, son abiertas comunicativamente y son apartadas a un lado, hasta que finalmente el ojo solo domina un mundo ordenado y neutralizado" (Gehlen 1980:52). De ahí que "el tender-hacia las cosas, sea independiente de la presencia real de las cosas" (Gehlen 1980:56). Consiguientemente las sensaciones táctiles producidas "en nuestro cuerpo desde afuera no se distinguen en absoluto, como tal, de otra originada por nosotros mismos, [lo único que las distingue es la falta de] las vivencias del movimiento del propio miembro que condujo a aquella posición" (Gehlen 1980:197).

La objetividad cósica de las cosas "es su 'estar-colocadas-alli', por cuanto que indican qué hay en ellas oculto de posibles consecuencias derivadas de tratar con ellas y de cualidades desarrollables" (Gehlen 1980:206). Lo que implica que la objetividad real de las cosas reales es un correlato del obrar o del querer, de modo que "la objetividad visible de las mismas cosas de la conciencia es un correlato del obrar o del querer posibles y de ninguna manera del puro pensar o mirar mismos" (Gehlen 1980:210). Hay una dualidad incancelable en la cosa: por "un lado, como la cosa misma, es material percibido: por otro lado, ha sido ordenado y creado por uno mismo" (Gehlen 1980:210). Los símbolos mismos son autoproducidos por la industria humana de modo que "ese dirigirse-uno-a-sí-mismo, hacia algo mediante un símbolo auto producido, se llama pensar, de donde hablar y pensar son al principio plenamente idénticos" (Gehlen 1980:275). En la misma línea, Blumenberg, a propósito de su célebre segunda ley de la 'inmediatez mediata', cuestiona el "sentido filosófico de preguntarse si puede darse algo fuera de la relación entre el ex-centro y el mundo externo e interno, pues en ella el hombre se agota, o mejor dicho, desvanece" (Menegazzi 2010:305). En la insistencia plessneriana de que al hombre su "mundo [le] está dado en las apariencias, en las que lo real se manifiesta refractado a través del médium de nuestros modos de percibir las cosas y de nuestras acciones [...], es precisamente esa refracción la que garantiza la inmediatez del contacto, pues 'el ojo, mientras ve, necesariamente se olvida de sí'” (Menegazzi 2010:305).

Por otra parte, sostenía tempranamente que "[e]l ser humano no tiene ninguna relación inmediata, puramente 'interior' consigo mismo. Su auto-comprensión tiene la estructura de la 'auto-exterioridad'" (Villacañas 2004:71). Por allí ve fluir Plessner la clave de bóveda de toda hermenéutica: "solo a partir de lo extraño, podrá el hombre ver algo en sí mismo" (Villacañas 2004:71). Aún más, "que el hombre se haya 
visto como imagen y semejanza de algo otro es la demostración de la imposibilidad de ese narcisismo originario que impide al hombre mirarse a sí mismo como figura original" (Villacañas 2004:71). Para el teórico de la metaforología, es sobre la base de nuestra constitución metafórica que "proyectamos sobre nosotros mismos lo que nos representamos de los otros. Somos metáforas de los otros, construidos sobre las analogías de lo que interpretamos" (Villacañas 2004:72). ¿Qué implica ello ahora para el conocimiento científico? Que la ciencia, más que dar al hombre una idea de su conocimiento, produce paradójicamente una idea más precisa de su ignorancia. Despojado de la exigencia del principio de razón suficiente y postulando el principio de razón insuficiente, Blumenberg concluye que desembarazado el hombre de tal primer principio, "solo le queda reconocerse como autoafirmación 'consciente' de sí" (Rincón 2008:252), dando de este modo el paso decisivo al "poner fin a la ilusión de que el mundo visible es el mundo real". Paradójicamente la ciencia misma "sella el 'fin de los signos' -el fin de la concepción del mundo como un universo de signos que tiene sentido inmediato o que, al menos, son interpretables. El mundo científico concluye- se presenta ante nosotros como un mundo mudo" (Raulet 2009:197).

\section{Del descentramiento de lo humano y del mundo al descentramiento de la sociedad}

Tanto Gehlen, como Plessner, Blumenberg, Marquard y Schelsky, no así, Scheler, tratan expresamente desde sus propios matices al interior de una común tradición, el fenómeno del descentramiento de lo humano. Incluso, algunos de ellos derivan sugerentes proyecciones del descentramiento de lo humano hacia el descentramiento de la sociedad.

Plessner es el primero en generar una sugerente proyección que funge para este punto (descentramiento de lo humano), como para la crítica al 'prejuicio humanista' en el campo de la sociología, que luego realizará Luhmann. Se trata de la crítica al antropocentrismo de la modernidad, desarrollada al tenor de su crítica a la idea de humanitas y al radicalismo utópico. A ambas críticas, sus investigaciones biológicofilosóficas le quitan sustento en tanto la condición biológica de la existencia humana torna superflua la pretensión de afirmar una humanitas, lo que es tanto como decir la pretensión de afirmar una naturaleza humana de carácter metafísico. Por su parte, el llamado radicalismo utópico que, expresado de diversas maneras, convoca a transformaciones radicales del mundo, es para Plessner atentatorio contra la vida misma. El animal deficitario no es capaz de tanto. De ahí su crítica al antropocentrismo de la modernidad lo que lleva a Borsari a comparar la filosofía de Plessner con la de Foucault y Derrida (no ha de sorprender entonces de ahí la conexión que se ha estudiado además con Luhmann y Deleuze).

Por su parte Gehlen observa lo que llama la 'disolución de la sociedad', tesis para la que encuentra apoyo, no solo en las ciencias contemporáneas, sino también en el arte. En la complejidad y opacidad de la sociedad moderna visualiza nuestro autor las razones para el apremio de la valía individual y la concomitante generación de expectativas ilimitadas, desarrollando accesorios compensatorios y padeciendo de las desventajas. El pensador institucionalista da por mostrado que el proceso de industrialización tiene un efecto dislocante sobre los fundamentos del orden y la moralidad, la cual gozaba de milenios de estabilidad. A diferencia de una sociedad en la que todavía se podía soñar con una revolución total del orden social, hoy nos encontramos ante el desafío de la coordinación en cuanto la sociedad moderna llega con él a ser comprendida como "constituida por una pluralidad de sistemas 
coordinados de las actitudes habitualizadas" (Gehlen 1980:147). La teoría gehleniana de la sociedad moderna muestra percatación de la funcionalización de la sociedad, de su descentramiento, del problema de la coordinación social, del resquebrajamiento de las instituciones tradicionales, con la consiguiente intemperie para el 'animal todavía no fijado', del decaimiento de las virtudes, de la confusión y el desconcierto que todas estas transformaciones conllevan.

Blumenberg, a su turno, anticipa el descentramiento del hombre, la destrucción del antropocentrismo, ya desde la conciencia medieval y su creación del nominalismo del siglo XIV. Es la misma imagen de mundo de la cristiandad medieval la que genera consecuencias no intencionales que fuerzan "al hombre a contar solo consigo mismo y ésa será la génesis de la autoafirmación moderna" (Rincón 2008:255). Desplazada la imagen metafísico-religiosa de mundo, por la nueva imagen científica de mundo, se abandona el antropomorfismo para no volver a encontrar en la evolución histórica de la Edad Moderna nada significativamente humano en la realidad. La realidad ha perdido su centro rector. Se instala así una dialéctica en la que el hombre llama, pero la realidad no atiende su llamada, dialéctica que conduce a la deshumanización del mundo.

Por su parte, Marquard llega al descentramiento de lo humano, la historia y el mundo, desde su crítica a la filosofía de la historia. Contra ella se dirige una de sus lapidarias advertencias: "Mientras que la filosofía de la historia intenta acelerar el curso de la historia, la antropología dirige su mirada a lo que en el ser humano no cambia ni es responsabilidad suya: a su naturaleza" (Marquard 2000:14). Frente a esas ficciones históricas se impone el escepticismo de Marquard, el cual "no toma partido por ninguna de estas dos disciplinas en conflicto, sino que permanece escéptico respecto a ambas". En la línea de su pragmatismo concluirá que el contar con "dos filosofías, ofrece la ventaja de quedar libre frente a ambas" (2000:13). 'Polimitismo ilustrado' llamará a "la capacidad de participar en muchas historias para poder ser libre frente a cada una de ella" (Marquard 2000:14). Polimitismo que se opone a la visión 'monomítica', dominante en la historia, que solo nos deja participar en una historia, la del progreso en la emancipación. Recordemos su conclusión irónica: "Menos mal que disponemos de la historiografía y de la novela para ampliar nuestro mundo de historias" (Marquard 2000:14). El descentramiento marquardiano se postula desde la imposibilidad del ser deficitario de vivir y contar una sola historia. iNo hay la historia de la humanidad! ¡Hay historias!

A su turno, Schelsky, de la mano de la constatación de la tendencia al cientificismo en todas las esferas de la vida, sostiene que la ciencia, a través de la agencia de su 'industria' ha convergido en la fabricación universal de un nuevo mundo. Allí donde los predecesores de la AFA, partiendo de la tesis del hombre como ser deficitario desde el punto de vista orgánico, derivaban la técnica como continuación artificial de sus órganos, Schelsky piensa que tal principio ya no sirve para explicar la esencia de la técnica moderna, porque no da sociológicamente cuenta del descentramiento moderno, al presuponer "una relación hombre-mundo en la que el hombre se enfrenta con la naturaleza, la domina y explota, mediante órganos que funcionan como herramientas" (Schelsky 1967:13). En el marco de la Escuela de Leipzig, Schelsky postula que el mundo técnico se caracteriza por dos dinámicas aparentemente contradictorias que hablan de la tensión generada por su descentramiento: la alienación del hombre, junto a su realización 
constructiva. De ahí que el desafío a las ciencias humanas y sociales sea conocer más claramente el núcleo de la nueva 'realidad de producción' de nuestro mundo (Schelsky 1967:16). Sin embargo, la sociología no ha de dejarse seducir por "la idea de que, como consecuencia de esta autocreación técnico-científica del hombre (...) existiría un 'plan universal de trabajo' (...), el que podríamos manejar o incluso concebir" (1967:18). El límite lo coloca no la modestia del sociólogo, sino el hecho de que todos aquellos intentos de preconcebir este proceso mediante una teoría política, filosófica o religiosa llegan muy pronto a la penosa situación de tener que manipular consigo mismo.

Pero Schelsky, a diferencia de su discípulo Luhmann, no saca al hombre al entorno de la sociedad en tanto considera que ella "no es ningún ser absoluto que descanse sobre sí mismo y que esté enfrentado al hombre, sino que es el hombre mismo en tanto ciencia y en tanto trabajo" (1967:18).

\section{Del funcionalismo de la AFA al funcionalismo de la equivalencia}

No es trivial para la afinidad aquí mentada, la común referencia a Malinowski, tanto de Gehlen como de Luhmann. A los dos les atrae el potencial del método funcional bajo el cual trabaja el antropólogo. Gehlen se interesa por el estudio de la estructura social de las culturas primitivas, bajo la hipótesis de que allí se encuentra una clave para comprender la sociedad moderna. Es de destacar que ya aquí encuentra él presupuesta la idea pragmática del hombre como solucionador de problemas: "la cultura [para Malinowski] es esencialmente un aparato instrumental, para resolver mejor los problemas concretos y específicos que le salen al encuentro en su medio ambiente cuando trata de satisfacer sus indigencias" (Gehlen 1980:459).

Para Gehlen, lo que se ha solido pasar por alto en la investigación científica es el presupuesto infundado de la lógica causalista. Allí donde todas las dimensiones de lo humano, incluido lo moral y lo espiritual, 'forman un sistema', en el que están co-ocurriendo simultáneamente, queda "excluida la pregunta acerca de las 'causas'; no existe ninguna dependencia causal de una característica con respecto a las demás: la inteligencia no ha 'producido' el lenguaje; o, al revés, el caminar erecto no ha producido la inteligencia" (Gehlen 1980:19). Aún más, para él "desde el punto de vista metódico es necesario observar aquí que el concepto de 'causa' ha de desaparecer por completo" (1980:19). Insistir en el causalismo conduce más bien al descrédito del pensamiento biológico. De ahí su adopción del método funcionalista. Su radical rechazo del causalismo, como rendimiento de la investigación biológica, le lleva a reclamar su sustitución "por un método circular en el que se conectan las condiciones explicativas de la acción" (Álvarez 1996:292) en cuanto el ser humano gehleliano es comprendido como un "organismo plástico en el que se conjuntan de manera dinámica y funcional una dimensión biológica y otra cultural” (Álvarez 1996:297).

Por su parte, al decir de Schelsky, las investigaciones etnológico-sociológicas desarrolladas bajo el método funcionalista han ejercido un gran influjo sobre la sociología (también sobre la psicología social), convergiendo en la formación de una imagen de lo humano que supera los límites de una disciplina. Es así que no duda en catalogar la tesis central de Malinowski como 'una tesis de la filosofía biológica' en cuanto afirma que "toda cultura tiene que satisfacer las necesidades fundamentales del hombre que tiene un fundamento vital, puramente biológico" (Malinowski citado en Schelsky 1967:47). El pensador alemán 
advierte que en la emergencia de este nuevo tipo de legalidades, siguiendo la lógica del método funcionalista malinowskiano, se abren insospechadas posibilidades comparativas entre los artificios creados por el hombre. En la mirada 'comparativa' en la autoconciencia del arte moderno, encuentra "analogías de estilo y de problemas entre la poesía, la pintura y la música de los últimos 50 años" (Schelsky 1967:115). Con él, siguiendo el reclamo de su maestro (Gehlen), el método se extrapola a la sociología, lo que al parecer llegará a convertirse en principio metódico basal de la arquitectura teórica del funcionalismo de la equivalencia de Luhmann en su reformulación del funcionalismo de Parsons.

\section{Conclusión}

La teoría sociológica se ha construido en una tensión permanente con la tradición filosófica: o bien marca sus discontinuidades con ella, o la invoca como título honorífico para exculpar sus comprensiones apresuradas. Creemos haber mostrado cómo una sociología, que se entiende en discontinuidad con la tradición filosófica, se puede apoyar en ella sin transformar la sociología en filosofía continuada por otros medios. Pensamos que la mentada afinidad electiva muestra un punto ciego en la teoría de Niklas Luhmann: el concepto de lo humano tras su sociología sistémica. ¿Habrá que asumir -parafraseando a Luhmann- que el intento de describir a la sociedad no puede hacerse, no sólo desde fuera de la sociedad, sino fundamentalmente desde fuera de una precomprensión de lo humano? Por las venas abiertas de esta metáfora de lo humano, subyacentes en el funcionalismo de la equivalencia: el ser humano como solucionador de problemas en un sentido trascendental, nos parece que reside la clave de bóveda para comprender una de las deudas intelectuales de la sociología Luhmanniana -habitualmente no explicitada-, que vendría a operar como condición de posibilidad de su arquitectura teórica.

De aquí que concordemos con Mascareño en que la novedad de la afinidad electiva puesta en evidencia, resida en que "la tradición véteroeuropea si aporta un concepto de lo humano altamente compatible con la contingencia del mundo, con la potencia negativa de lo no actualizado" (Mascareño 2012:20).

En la tradición de la antropología filosófica alemana, el ser humano es un ser carencial, deficitario, no fijado, descentrado, abierto al mundo, cuya tarea primaria es hacerse cargo de sí mismo y para el cual la sociedad constituye su propio devenir (Adorno), su propio suplemento (Derrida), su propio mecanismo de reducción de complejidad (Luhmann).

Se trata entonces de que la técnica de la afinidad electiva ha permitido, dirigiendo la mirada a las raíces no sistémicas del funcionalismo de la equivalencia, dar un paso más allá de las conocidas raíces cibernéticas, fenomenológicas e, incluso, postestructuralistas de la teoría del sociólogo alemán. Para decirlo con una metáfora habermasiana, la 'chispa' que enciende su teorizar sociológico hay que inteligirla en el teorizar filosófico de la Antropología Filosófica Alemana. Pero tal técnica ha permitido, a su vez, desarrollar -al decir de Mascareño- "una forma metodológica novedosa de entender teórica, histórica y filológicamente las relaciones entre sociología y filosofía (...) - una forma que debe ser de interés para quienes piensen que la filosofía tiene algo o mucho que decir a la sociología y para todo el que asuma que la sociología es más que recolección de datos y descripción de hechos" (2012:20). En suma, creemos que con esta observación de segundo orden se abre espacio a una nueva comprensión del antihumanismo 
teórico de Luhmann: el "negativamente humanista antihumanismo teórico de su pensamiento, del cual la AFA es su oculto valor reflexivo" (Mascareño 2012:21) (2).

\section{Notas}

(1) Un desarrollo extenso y pormenorizado puede leerse en Miranda (2012).

(2) Este artículo es producto del proyecto de investigación Fondecyt № 1110428.

\section{Bibliografía}

Álvarez, L. 1996. Actualidad de la antropología filosófica de A. Gehlen. Thémata. Revista de Filosofía 17: 289-304.

Fischer, J. 2009. Exploring the core identity of philosophical anthropology through the works of Max Scheler, Helmuth Plessner, and Arnold Gehlen. Iris I: 153-170.

http://academicpublishingplatforms.com/downloads/pdfs/iris/volume1/201201030938 IRIS Vol1 No1 2009 7.pdf

Flórez, M. 2003. Hans Blumenberg: the borders of hermeneutics. Azafea. Rev. filos. 5: 263-270.

Fuster, F. 2009. 'Afinidades electivas' entre literatura y sociología: el suicidio de Andrés Hurtado en el árbol de la ciencia como ejemplo de suicidio anómico. EPOS 25: 61-75.

http://e-spacio.uned.es/fez/eserv.php?pid=bibliuned:Epos-2009-25-5040\&dsID=Documento.pdf

Gehlen, A. 1980. El hombre. Su naturaleza y su lugar en el mundo. Salamanca: Ediciones Sígueme.

Goethe, J. 2000. Las afinidades electivas. Madrid: Alianza Editorial.

González Cantón, C. 2004. La metaforología en Blumenberg, como destino de la analítica existencial. Madrid: Universidad Complutense de Madrid. http://eprints.ucm.es/tesis/fsl/ucm-t27802.pdf

Greene, M. 1966. El concepto de posicionalidad. Introducción a la filosofia de Helmuth Plessner. Convivium 22: 39-61.

Luhmann, N. 1973. Ilustración sociológica y otros ensayos. Buenos Aires: SUR.

Luhmann, N. 1997. Organización y decisión. Autopoiesis, acción y entendimiento comunicativo. Barcelona: Anthropos

Luhmann, N. 2007. La sociedad de la sociedad. México: Herder.

Marquard, O. 2000. Apología de lo contingente. Valencia: El Magnánim. 
Mascareño, A. 2012. Prefacio. En: P. Miranda. 2012. La precomprensión de lo humano en la sociología de Luhmann. Raíces antropológicas del anti-humanismo teórico luhmanniano. Santiago, Ediciones Universidad Alberto Hurtado.

Menegazzi, T. 2010. Helmuth Plessner: antropología y bio-filosofía a comienzos del siglo XX. Thémata. Revista de Filosofía 43: 289-315. http://institucional.us.es/revistas/themata/43/16Menegazzi.pdf

Miranda, P. 2012. La pre-comprensión de lo humano en la sociología de Luhmann. Raíces antropológicas del antihumanismo teórico luhmanniano. Santiago: Ediciones Universidad Alberto Hurtado.

Pansera, M. T. 2005. El paradigma antropologico di Arnold Gehlen. Roma: Babel Mimesis.

Raulet, G. 2009. La filosofía alemana después de 1945. Valencia: Universitat de València.

Rincón, A. 2008. La obra póstuma de Blumenberg: Beschreibung des Menschen. Isegoría. Revista de Filosofía Moral y Política 39: 251-265.

http://isegoria.revistas.csic.es/index.php/isegoria/article/download/632/633

Scheler, M. 1938. El puesto del hombre en el cosmos. Buenos Aires: Editorial Losada.

Schelsky, H. 1967. El hombre en la civilización científica: y otros ensayos. Buenos Aires: Sur.

Sobrevilla, D. 2006. El retorno de la antropología filosófica. Discusiones y notas. Diánoia 56: 95-124. http://dianoia.filosoficas.unam.mx/files/7613/6019/6008/DIA56 Sobrevilla.pdf

Villacañas, J.L. 2004. De nobis ipsis silemus. Reflexiones sobre Hans Blumenberg, lector de Kant. Daimon. Revista de Filosofía 33: 65-77. http://revistas.um.es/daimon/article/viewFile/15501/14961

Weber, M. 2003. La ética protestante y el espíritu del capitalismo. México: Fondo de Cultura Económica.

Recibido el 1 Abr 2014

Aceptado el 25 Jun 2014 